\title{
Appraisal of Lead and Cadmium in the Caprines of Goats (Capra aeggarus hircus) Slaughtered in Ibadan, Nigeria
}

\author{
Emmanuel Tyokumbur ${ }^{*}$, Joyce Iornumbe \\ Department of Zoology, University of Ibadan, Ibadan, Nigeria \\ Email address: \\ e.tyokumbur@mail.ui.ed.ng (E. Tyokumbur) \\ ${ }^{*}$ Corresponding author
}

To cite this article:

Emmanuel Tyokumbur, Joyce Iornumbe. Appraisal of Lead and Cadmium in the Caprines of Goats (Capra aeggarus hircus) Slaughtered in Ibadan, Nigeria. American Journal of Biomedical and Life Sciences. Vol. 5, No. 1, 2017, pp. 1-5. doi: 10.11648/j.ajbls.20170501.11

Received: January 5, 2017; Accepted: January 12, 2017; Published: February 4, 2017

\begin{abstract}
A study was carried out on the appraisal of lead and cadmium in the caprines of goats in Ibadan, Nigeria between June and September 2016. Caprines from six goats were collected from Bodija market in Ibadan. A total of 36 samples (Liver, lungs, oesophagus, intestines, heart and muscle) were used in the study. The samples were ashed in a furnace at a temperature of $400^{\circ} \mathrm{C}$ for two hours for each batch and stored in sample bottles prior to acid digestion. The heavy metals lead $(\mathrm{Pb})$ and cadmium (Cd) were then analyzed using Buck Scientific Atomic Absorption Spectrophotometer (AAS). Each analysis was done in triplicates while standard and blank samples were analyzed for all the 36 samples. The results showed that the highest $\mathrm{Cd}$ concentration was found in the liver $(0.06 \mathrm{ppm})$ in sample 5 and in the heart of sample $6(0.06 \mathrm{ppm})$ which exceeded the WHO guideline limit of $0.05 \mathrm{ppm}$. The highest concentration of $\mathrm{Pb}$ was found in the heart of sample $1(0.63 \mathrm{ppm})$, the liver of sample $2(0.42 \mathrm{ppm})$, the lungs of sample $3(0.83 \mathrm{ppm})$ and the liver of sample $4(0.33 \mathrm{ppm})$ all of which exceeded the WHO set limit of $0.01 \mathrm{ppm}$. The study showed that the consumption of caprines and meat (muscle) from goats slaughtered in in Ibadan is relatively safe. It is therefore recommended that there should be regular biomonitoring of heavy metals in the caprines and meat from livestock slaughtered in Ibadan, Nigeria for public health safety.
\end{abstract}

Keywords: Lead, Cadmium, Caprines, Goats, Ibadan

\section{Introduction}

Our environment is impacted by a wide variety of pollutants $[1,2]$. The health risks associated with environmental contaminants depends on several factors including absorption and toxicity of substance, its level in food, the quantity of contaminated food consumed and duration of exposure [2]. Another challenging factor concerning chemical contaminants is that the toxicity of contaminants must be frequently extrapolated from animal studies [3]. One of the most important aspects of environmental pollution is that people take up many pollutants through the food chain. Animals are a rich source of food but also a rich source of contaminants [4]. It is also important to carry out complex studies dealing with potential elimination of these contaminants and their negative influence on live organism [5]. Heavy metal pollution is likely to reach disturbing levels because adequate efforts are not made towards managing waste and protecting the environment in its entirety as urbanization and Industrialization continues to evolve and gain grounds especially in West Africa [6]. In Nigeria, the use of automobiles by almost all cadres of the society is high. This amongst other factors such as growth in industrialization is gradually leading to environmental deterioration. Thus, Industrialization and heavy metal pollution are positively correlated [7]. Nigeria is an oil exporting country and the petroleum produced here contains $>0.45 \mathrm{~g} / 1$ lead using the Nigerian Industrial Standard (NIS 116:1981). Gasoline with average lead content of $0.66 \mathrm{~g} / \mathrm{L}$ remains in use. With high automobile importation, the national consumption of petroleum in the country is estimated at 20million litres per day, with about 150 people/car/city, therefore close to $15,000 \mathrm{Kg}$ of lead is emitted into the environment through combustion daily. Heavy metal pollution is posing a serious problem in Nigeria, threatening animals, human health and quality of the environment [8]. Food safety is a major public 
health concern worldwide. The risk of heavy metal contamination in meat is of great concern for both food safety and human health because of the toxic nature of these metals at relatively minute concentrations [7].

In recent times, there has been considerable interest in the level of heavy metallic elements in food because of their harmful effects on human health [9]. These heavy metals in food and drinking water amounts to approximately $80 \%$ for cadmium, $40 \%$ for lead and $8 \%$ for mercury [10]. Metal contamination in food especially meat have been broadly investigated [11]. The main sources of human exposure to lead and cadmium is through food which is believed to account for approximately $30 \%$ and water of $10 \%$ [12].

The aim of this study is to evaluate the assess lead and cadmium in the caprines of goats slaughtered and sold in Bodija market in Ibadan, Nigeria. The objectives of this study are to determine the concentrations of lead and cadmium in the caprines of goats slaughtered in Bodija market in Ibadan and to compare the obtained results with the World Health Organization (WHO) permissible limits of lead and cadmium in food.

\section{Materials and Methods}

\subsection{Study Area}

This study was carried out in Ibadan city which is the capital of Oyo State of Nigeria. It is located near the grassland boundary of South Western Nigeria at a distance of 145 kilometres North East of Lagos. The total area of the city is approximately 103.8 square kilometres It has an estimated population of 3.5 million from current projections based on 2006 National census. The Ibadan region comprises of 11 Local government areas and it can generally be rated as a highly industrialised city.

\subsection{Sample Collection and Processing}

Caprines from six goats were collected from Bodija market in Ibadan city. A total of 36 samples (Liver, oesophagus, lungs, intestines, heart and muscle) were used in the study. Sample collection, preparation and analyses were carried out between the months of June and September 2016.

Samples were collected from Bodija market and taken to the laboratory for ashing. The samples were ashed in a furnace at a temperature of $400^{\circ} \mathrm{C}$ for two hours for each batch of samples. The ashes were stored in sample bottles prior to wet digestion. $0.5 \mathrm{~g}$ of each dried sample was digested with $2 \mathrm{ml}$ of $70 \%$ Nitric acid and allowed to stay overnight. After 24 hours, $1 \mathrm{ml}$ of $30 \%$ hydrogen peroxide was added to each of the digested sample in the ratio of $2: 1$ and allowed to simmer down. Following the digestion, the solution was filtered using acid-resistant filter papers into acid-rinsed polyethylene bottles. The digestion was made up to $10 \mathrm{ml}$ mark with distilled water and taken for analysis.

\subsection{Heavy Metal Analysis}

The concentration of lead and Cadmium were determined using Buck Scientific Atomic Absorption Spectrophotometer. Each analysis was done in triplicates while standard and blank samples were analysed for all the 36 samples. The results will be expressed in parts per million (ppm).

\subsection{Statistical Analysis}

The data will be represented as means and standard deviation of lead and cadmium in the caprines of the slaughtered goats in Bodija market in Ibadan, Nigeria. Histograms will be plotted to show the comparison between the concentration of lead and cadmium for each of the sample. The results will be compared with WHO guideline limit to indicate the disparity.

\section{Results}

\subsection{Concentration of Lead and Cadmium in the Caprines of Goats in Bodija Market}

The mean and standard deviation of Cd concentration in the caprines of goats from the study is shown in Table 1, while $\mathrm{Pb}$ was mostly undetected in the organs but occurring in only one caprine of the sample as reported below.

Table 1. Concentration of $C d$ in the sampled caprines of goats from the study (ppm).

\begin{tabular}{|c|c|c|c|c|c|c|c|c|}
\hline $\begin{array}{l}\text { Caprine } \\
\text { Sample } \\
\end{array}$ & Liver & Lung & Muscle & Heart & Oesophagus & Intestine & Mean & Standard deviation \\
\hline 1 & 0.01 & nd & 0.03 & 0.01 & nd & 0.01 & 0.01 & 0.011 \\
\hline 2 & 0.04 & 0 & 0.04 & 0.01 & nd & 0.01 & 0.166 & 0.019 \\
\hline 3 & nd & 0.05 & 0 & 0.01 & 0.03 & 0.03 & 0.025 & 0.02 \\
\hline 4 & nd & nd & 0.02 & nd & nd & 0.02 & 0.0066 & 0.01 \\
\hline 5 & 0.06 & 0.04 & 0.02 & 0.04 & 0.01 & 0.02 & 0.122 & 0.018 \\
\hline 6 & nd & 0.02 & 0.03 & 0.06 & 0.02 & 0.01 & 0.0233 & 0.02 \\
\hline
\end{tabular}

nd $=$ not detected.

The highest concentration of $\mathrm{Cd}$ was recorded in the muscle $(0.03 \mathrm{ppm})$ while the lowest concentrations were found in the liver, heart and intestine $(0.01 \mathrm{ppm})$ in sample 1 . $\mathrm{Cd}$ was not detected in the lungs and oesophagus. The highest concentration of $\mathrm{Pb}$ in sample 1 was recorded in the heart $(0.63 \mathrm{ppm}) . \mathrm{Pb}$ was not detected in the liver, lungs, muscle, oesophagus, intestine and heart. In sample 2, the highest concentration of $\mathrm{Cd}$ was recorded in the liver and muscle $(0.04 \mathrm{ppm})$ while the lowest concentration was found in the heart and intestine $(0.01 \mathrm{ppm})$. Cd was not detected in 
the lung and oesophagus. The highest concentration of $\mathrm{Pb}$ in sample 2 was recorded in the liver $(0.42 \mathrm{ppm}) . \mathrm{Pb}$ was not detected in the lungs, muscle, oesophagus, intestine and heart. The highest concentration of $\mathrm{Cd}$ was recorded in the lungs $(0.05 \mathrm{ppm})$ while the lowest concentration was found in the heart in sample 3. Cd was not detected in the liver and muscle. The highest concentration of $\mathrm{Pb}$ in sample 3 was recorded in the lungs $(0.83 \mathrm{ppm})$ while in the liver, muscle, heart oesophagus and intestine, $\mathrm{Pb}$ was not detected. In sample 4, the highest concentration of $\mathrm{Cd}$ was recorded in the intestine and muscle (0.02) while it was not detected in the liver, lungs, heart and oesophagus.

The highest concentration of $\mathrm{Pb}$ in sample 4 was recorded in the liver $(0.33 \mathrm{ppm})$ while in the lungs, muscle, intestine, heart and oesophagus, $\mathrm{Pb}$ was not detected. In sample 5, the highest concentration of $\mathrm{Cd}$ was recorded in the liver $(0.06 \mathrm{ppm})$ while the lowest concentration was found in the oesophagus $(0.01 \mathrm{ppm})$. The highest concentration of $\mathrm{Pb}$ in sample 5 was recorded in the liver $(0.33 \mathrm{ppm})$ while in the lungs, muscle, heart, oesophagus and intestine, it was not detected. The highest concentration of $\mathrm{Cd}$ was recorded in the heart (0.06) while the lowest concentration was found in the intestine $(0.01 \mathrm{ppm})$ in sample 6 . The highest concentration of $\mathrm{Pb}$ in this was recorded in the muscle $(0.01 \mathrm{ppm})$ while it was not detected in the intestine, oesophagus, lung, liver and heart. In all, the muscle had the highest mean concentration of $\mathrm{Cd}$ as compared to other organs and tissues in the following order muscle $>$ liver $>$ heart $>$ intestine $>$ oesophagus $>$ lungs.

\subsection{Comparison of Concentration of $\mathrm{Pb}$ and $\mathrm{Cd}$ in the Caprines with WHO Guideline Limits.}

The results of the mean $\mathrm{Cd}$ concentration in the caprines studied is shown in Figure 1. The highest mean concentration was recorded in the liver, lungs, muscle, heart and intestine $(0.02 \mathrm{ppm})$, while the least was in the oesophagus $(0.01 \mathrm{ppm})$. All the mean $\mathrm{Cd}$ concentration in the caprines and muscle were below the World Health Organization (WHO) guideline limit of $0.05 \mathrm{ppm}$ [13].

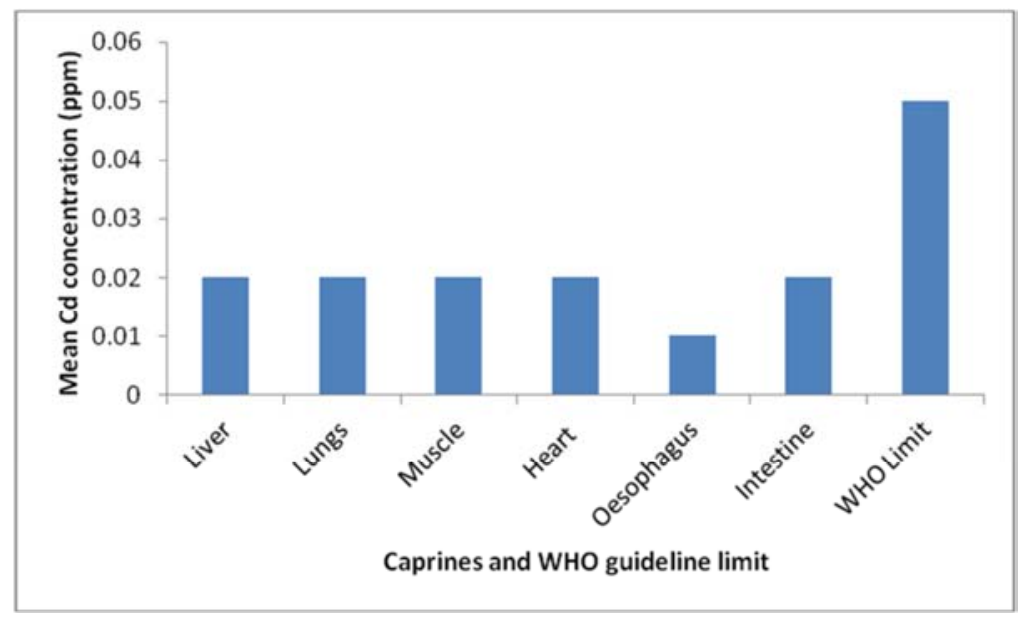

Figure 1. Mean Cd concentration in the caprines and WHO guideline limit.

The results of the mean $\mathrm{Pb}$ concentration in the caprines is shown Figure 2. The highest mean $\mathrm{Pb}$ concentration in the caprines was in the lungs $(0.14 \mathrm{ppm})$, while the least was in the muscle $(0.01 \mathrm{ppm})$. It was not detected in the intestines and oesophagus of all the samples. The mean concentration of $\mathrm{Pb}$ in the liver, lungs and heart exceeded the WHO guideline limit of $0.1 \mathrm{ppm}$ [13], while in the muscle (0.01ppm) was below it.

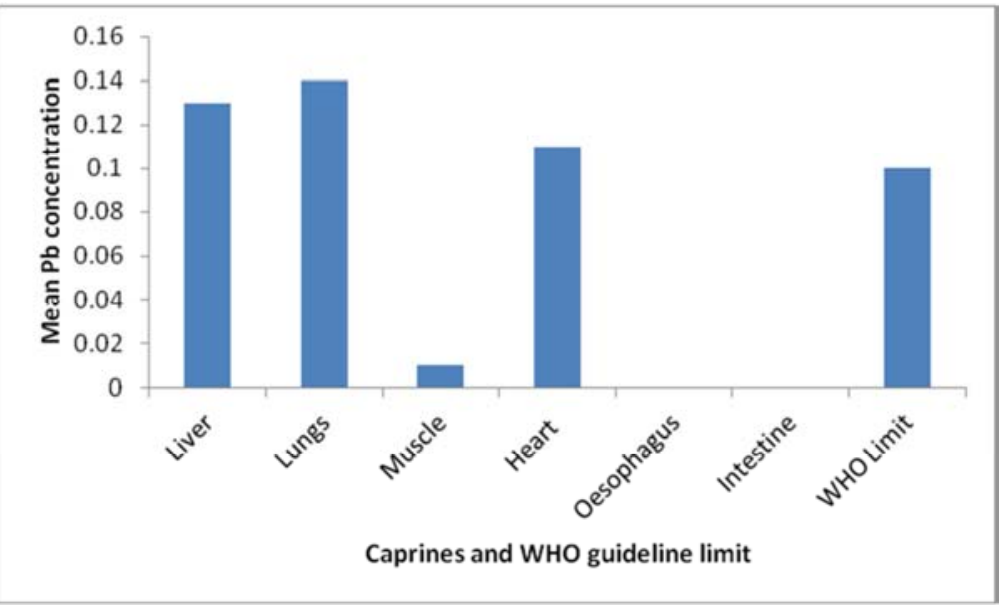

Figure 2. Mean Pb concentration in the caprines and WHO guideline limit. 


\section{Discussion}

\subsection{Distribution of Lead and Cadmium Metals in the Caprines of Goats.}

The results obtained from this study indicated that $\mathrm{Cd}$ concentrations in the caprines of goats collected from Bodija market Ibadan was insignificant while there was variability in the distribution of $\mathrm{Pb}$ metal in the caprines, although the variations in the values obtained was minimal.

\subsection{Human Consequences of Consuming Goat Meat in Ibadan}

From the results obtained, the concentrations of $\mathrm{Pb}$ in the caprines of the goats obtained exceeded the WHO/FAO permissible limit of $0.05 \mathrm{ppm}$ in the heart of sample 6 and the liver of sample 5. Cd in the goat samples was below the FAO/WHO permissible limits of $0.1 \mathrm{ppm}$ for the tested samples, except in the heart of sample 1 $(0.63 \mathrm{ppm})$, liver of sample $2(0.42 \mathrm{ppm})$, lung of sample 3 $(0.83 \mathrm{ppm})$, liver of sample $4(0.33 \mathrm{ppm})$. Similar findings have been reported by Akan [7] in a study on the distribution of heavy metals in the liver, kidney and meat of beef, mutton, caprine and chicken from Kasuwan Shanu Market in Maiduguri Metropolis, Borno State Nigeria. Hence, consumption of goats from Bodija market is relatively safe except the heart, liver and lungs. The high concentration of $\mathrm{Cd}$ and $\mathrm{Pb}$ in some of the caprines is due to level of exposure, ingestion by life goats and even at the points of slaughter and the physiological activities of the organs and tissues involved. For example, the heart helps in circulation of blood and other materials around the body. Unwanted materials such as heavy metals can be trapped during this process. The liver is the site of detoxification. Toxins and other harmful substances can be trapped during this process. The lungs play a role respiration during the process of respiration, air is being filtered. Toxic materials from contaminated air can be trapped in the lungs during this process [2]

\section{Conclusion and Recommendation}

All the samples collected were safe for human consumption except for heart and lung, which were above recommended limits set by FAO/WHO (2002/2004). The relative safety of consuming goats from Bodija market in Ibadan is due to poor industrialisation in the areas where they are raised and hence low discharge of heavy metals and subsequently safe exposure and intake by the livestock. However, continuous monitoring and surveillance should be used as bioaccumulation of $\mathrm{Pb}$ and $\mathrm{Cd}$ could lead to serious health problems among consumers as earlier discussed in the literature review.

In addition, garlic could be used to antagonize $\mathrm{Pb}$ toxicity as it contains chelating compounds capable of enhancing the elimination of $\mathrm{Pb}$. Medical chelation programmes and consumption of fruits and vegetables rich in Vitamin-C could aid in the excretion of $\mathrm{Pb}$ from humans that have accumulated the heavy metal in their systems. Use of leaded products in Nigeria should be banned because of its toxic effects on humans and animals. Industries should be sited far away from animal pens and livestock houses because exposure of livestock to high levels of $\mathrm{Cd}$ and $\mathrm{Pb}$ can trigger adverse effects such as reproductive impairment, physiological abnormalities, behavioural modifications and even death. Therefore, animal's water, source of air and food should be monitored closely through biomonitoring programmes for $\mathrm{Pb}$ and $\mathrm{Cd}$ to avoid exposure to these highly toxic metals.

\section{References}

[1] Massaro, E. J., (1997). Handbook of Human Toxicology, CRC Press LLC, New York, pp. 47. 49; 118- 380; 966-1057.

[2] El-Salam, N. M. A., S. Ahmad, A. Basir, A. K. Rais, A. Bibi, R. Ullah and Hussain, I.(2013). Distribution of heavy metals in the liver, kidney, heart, pancrease and meat of cow, buffalo, goat, sheep and chicken from Kohat market Pakistan. Life Science Journal. 10 (7s).

[3] Smirjakova, S., Ondrasovicova, O., Kaskova, A. and Latktikova, K. (2005). The effects of cadmium and lead pollution on human and animal health. Supplementum, S31S32. 2005.

[4] Strmiskova, G. (1992). Lead in the Enviroment and Food (Slovak). Nutrition and Health, 37, 19-20.

[5] Zelenik J.(1994). Occurrence of heavy metals in smoked meat products (Slovak), Attestation Thesis, Institute for Education of Veterinary Surgeons Kosice, 46pp.

[6] Babalola, O. O., Ojo L. O., and Aderemi, M. O., (2005). Lead levels in some biological samples of automechanics in Abeoukuta, Nigeria. Indian J. Biochem. Biophys. (42): 401403.

[7] Akan, J. C., Abdulrahman, F. L., Sodipo, A. L., and Chirom Y. A. (2010). Distribution of heavy metals in the liver, kidney and meat of beef, mutton, caprine and chicken from Kasuwan Shanu Market in Maiduguri Metropolis, Borno State Nigeria. Research Journal of Applied Sciences, Engineering and Technology. 2 (8): 743-748.

[8] Dekofehiniti, O. O., Omotoyi, I. O., Oloremu, A. G., and Abayomi, T. G., (2012). Heavy metal distribution and lipid profile in the stomach of cows grazed in Akungba- Akoko, Ondo State Nigeria. African Journal of Biochemistry Research. (6): 146-149.

[9] Okoye, C. O. B. and Ibeto C. N. (2008). Book of proceeding of the 31 st Annual International Conference of the Chemical Society of Nigeria, Chemical Society of Nigeria: Warri; 2008, pp 767-771.

[10] Bennet, F. G. (1984). Modelling exposure roots of trace elements from sources to animal health. Springer Verlag Berlin. 345-356. 
[11] Hassan, A. R., Saleh, M., Sobih, M., Wilson, S., and Reddy, P. (1998). Effects of some heavy metal pollutants on the performance and immune system of chicks. Poultry Science (77): 24-30.

[12] John, H. H. and Jeanne, I. R., (2004). Food additives, contaminaants and natural toxins. In: Maurice E. S., A.,
James, O., Moshe, S. L., and Febiger, (Eds). Modern Nutrition in Health and Disease. 8th Edn., Part ii, pp: 1597- 1598.

[13] WHO (2004). Background document for development of WHO Guidelines for Drinking Water Quality. World Health Organization, Geneva. 